\title{
High-Resolution Numerical Model for Predicting the Transport and Dispersal of Oil Spilled in the Black Sea
}

\author{
Konstantin A. Korotenko ${ }^{1, *}$, Malcolm J. Bowman ${ }^{2}$, and David E. Dietrich ${ }^{3}$ \\ ${ }^{1}$ P.P. Shirshov Institute of Oceanology, Moscow, Russia \\ ${ }^{2}$ School of Marine and Atmospheric Sciences, State University of New York, Stony Brook NY, USA \\ ${ }^{3}$ AcuSea, Inc., La Jolla CA, USA
}

Received 20 September 2008, accepted 24 April 2009

\begin{abstract}
The coupled DieCAST-SSBOM (Shirshov-Stony Brook Oil spill transport Model) circulation-oil spill transport model is used to predict the transport and dispersal of contaminants resulting from representative hypothetical oil spills in the Black Sea. With climatological forcing, the DieCAST model realistically simulates many of the dominant mesoscale features of seasonally-varying large scale circulation and meso-scale features of the circulation including the Rim Current, anticyclonic coastal eddies, headland eddy shedding and vertical stratification. The oil spill model ingests DieCAST surface currents and employs a Lagrangian tracking algorithm to predict the motion of a large number of seeded particles, the sum of which $(\sim 1$ million) form the oil plume. Basic processes affecting the transport of oil and its fate (advection, sinking, evaporation, etc.) are included as parameters. Various scenarios of hypothetical blowouts of oil in different regions of the sea are simulated and discussed as to their structure, transport and likelihood of coastal contamination. The ultimate objective is to develop an operational oil slick model forced with synoptic winds and air-sea interaction.
\end{abstract}

Key words: Black Sea, Oil pollution, Circulation, Coastal anticyclonic eddies, Numerical modeling

Citation: Korotenko, K. A., M. J. Bowman, and D. E. Dietrich, 2010: High-resolution numerical model for predicting the transport and dispersal of oil spilled in the Black Sea. Terr. Atmos. Ocean. Sci., 21, 123-136, doi: 10.3319/TAO.2009.04.24.01(IWNOP)

\section{INTRODUCTION}

\subsection{Oil Pollution in the Black Sea}

The Black Sea presently faces strong ecological disequilibria owing to eutrophication and pollution arising from many contaminants injected principally from rivers discharging into the basin, atmospheric deposition, direct discharges from point and non-point coastal sources and occasional accidents at sea. Major contaminants include oil residues, pesticides, hydrocarbons, nutrients and heavy metals. Accidental spills of the contaminants pose a very high level of risk for the marine environment and coastline, as the Black Sea is essentially a closed basin and thus very sensitive to continued high fluxes of contamination.

Among the most damaging spills are those resulting from collisions and groundings of oil tankers whilst in transit as well as accidental spills at oil terminals and damage

\footnotetext{
* Corresponding author

E-mail: kkoroten@yahoo.com
}

to coastal pipelines (Korotenko et al. 2003). The annual amount of oil released into the Black Sea is $~ 110000$ tons (Stoyanov et al. 1999). Table 1 summarizes estimates of oil contamination emanating from those countries surrounding the Black Sea. A rising threat of sea borne accidents is emerging as oil tanker traffic increases from accelerated exploitation of the oil fields of Azerbaijan, Kazakhstan, the Russian Federation, and Turkmenistan.

During the next decade, industry projections indicate that about 2 billion tons of oil will be extracted and processed in these countries. Transporting this cargo by ship across the Black Sea to Mediterranean ports and beyond will require more than 32000 additional oil tanker trips. Inevitably, the danger of oil spills will rise, particularly during extreme weather events.

As an example, on 12 November 2007, a serious series of accidents occurred in the Kerch Strait during a violent storm wherein strong winds, gusting to $75 \mathrm{mph}$, coupled 
Table 1. Oil Input to the Black Sea (tons $\mathrm{yr}^{-1}$ ).

\begin{tabular}{|c|c|c|c|c|c|c|c|}
\hline Sources of Pollution & Bulgaria & Georgia & Romania & $\begin{array}{c}\text { Russian } \\
\text { Federation }\end{array}$ & Turkey & Ukraine & Total \\
\hline Domestic & 5649.00 & & 3144.10 & & 7.30 & 21215.90 & 30016.30 \\
\hline Industrial & 2.72 & 78.00 & 4052.50 & 52.78 & 752.86 & 10441.00 & 15379.86 \\
\hline Land-based & & & & 4200.00 & & 5169.20 & 9369.20 \\
\hline Rivers & 1000.00 & & & 165.00 & & 1473.00 & 2638.70 \\
\hline Total & 6651.72 & 78.00 & 7196.60 & 4418.48 & 760.16 & 38299.10 & 57404.06 \\
\hline
\end{tabular}

with high surf caused ten vessels to sink and many others to run aground in the strait and the northern Black Sea region. This included the sunk tanker Volganeft-139, which was loaded with nearly 1.3 million gallons ( 5000 tons) of fuel oil. Nearly half that amount spilled into the strait and washed up on nearby shorelines. The Nakhichevan, one of two freighters that broke up, split in two, spilling 2000 tons of fuel oil into the Kerch Strait.

The plume moved generally toward the Ukrainian coast, consistent with the mean circulation of the Black Sea. According to Oleg Mitvol (former deputy head of Russia's environmental regulator and a member of the United Nations' International Panel for Sustainable Resource Management), at the time stated that the sinking of the ships in the Kerch Strait was a serious disaster and that it could take 10 to 15 years to clean up the strait and its coastline (http:// edition.cnn.com/2007/WORLD/europe/11/12/russia.ships/ index.html).

The transport and dispersal of oil in a marine environment are complex processes that depend on a number of factors determined by the ambient environmental conditions and the properties of the oil, itself. To formulate a realistic model of the transport and fate of oil slicks in the sea, it is necessary to accurately reproduce circulation and exchange processes, coupled with an adequate description of the physico-chemical properties of oil, and the environmental characteristics of its sources and sinks.

\subsection{Mesoscale Features of the Black Sea}

Figure 1 is a generalized composite image of surface circulation in the Black Sea, based on historical measurements, satellite imagery and numerical models (e.g., Oguz et al. 1994; Krivosheya et al. 2000; Staneva et al. 2001; Ginsburg et al. 2002a, b; Zatsepin et al. 2003). Basically, the structure of the circulation is composed of a seasonally varying (weaker in summer, stronger in winter) counter-rotating (cyclonic) Rim Current (RC) surrounded by many predominantly anticyclonic coastal eddies (ACEs) wedged between the $\mathrm{RC}$ and the continental shelf (not all those eddies shown in Fig. 1 occur at the same time, but they are very persistent features). The structure of the RC and its contribution to oil spill transport is discussed in Korotenko et al. (2003).

Based on the climatology of the RC, it is possible to arrive at first order estimates of the general trajectory of an oil spill plume released at a specific point in the interior of the Sea. Improved estimates would be obtained using observed the weather conditions at the time of the spill, hydrography (especially stratification of the water column in the upper $100 \mathrm{~m}$ ), circulation and mixing processes of the Black Sea, including its cyclonic interior, the $\mathrm{RC}$ itself and the coastal eddies with their associated exchange of near-shore and slope waters. The latter is especially important since most accidents occur near and in ports, sea straits and oil terminals. Also, as stated above, many pollutants enter the sea via river discharges.

Observations show that the ACEs have a preponderance to form in the summer and autumn. Typically, ACEs are close to circular in shape with diameter $\sim 30-60 \mathrm{~km}$. After their formation from baroclinic instabilities and von Karman-type shedding from south of the Crimean peninsula near Sebastopol (Fig. 1), most of the ACEs remain trapped and "roll" along the coast like "lubrication eddies" in the same direction as the RC (counterclockwise). In the far eastern reaches of the Black Sea, ACEs can grow and fill the entire eastern corner of the Black Sea, remaining trapped there for several months. The so-called Batumi anticyclonic eddy (BAE - Fig. 1) may grow to a terminal diameter of $\sim 100 \mathrm{~km}$ over some months as a result of mergers of smaller, deaccelerating anticyclonic eddies and filaments arriving from upstream (imbedded in slope waters to the west) before being absorbed back into the Rim Current. The so-called Sebastopol anticyclonic eddy (SAE) is periodically generated (with a period of $\sim 3$ weeks) by intense vorticity generation over the very steep continental margin lying to the south of the Crimea Peninsula. The largest SAEs grow to $\sim 100-$ $150 \mathrm{~km}$ in diameter, with a thickness of $\sim 100-200 \mathrm{~m}$ (Korotenko et al. 2003).

Once shed, these eddies are then embedded into the Rim Current and transported around the northeastern slopes, 


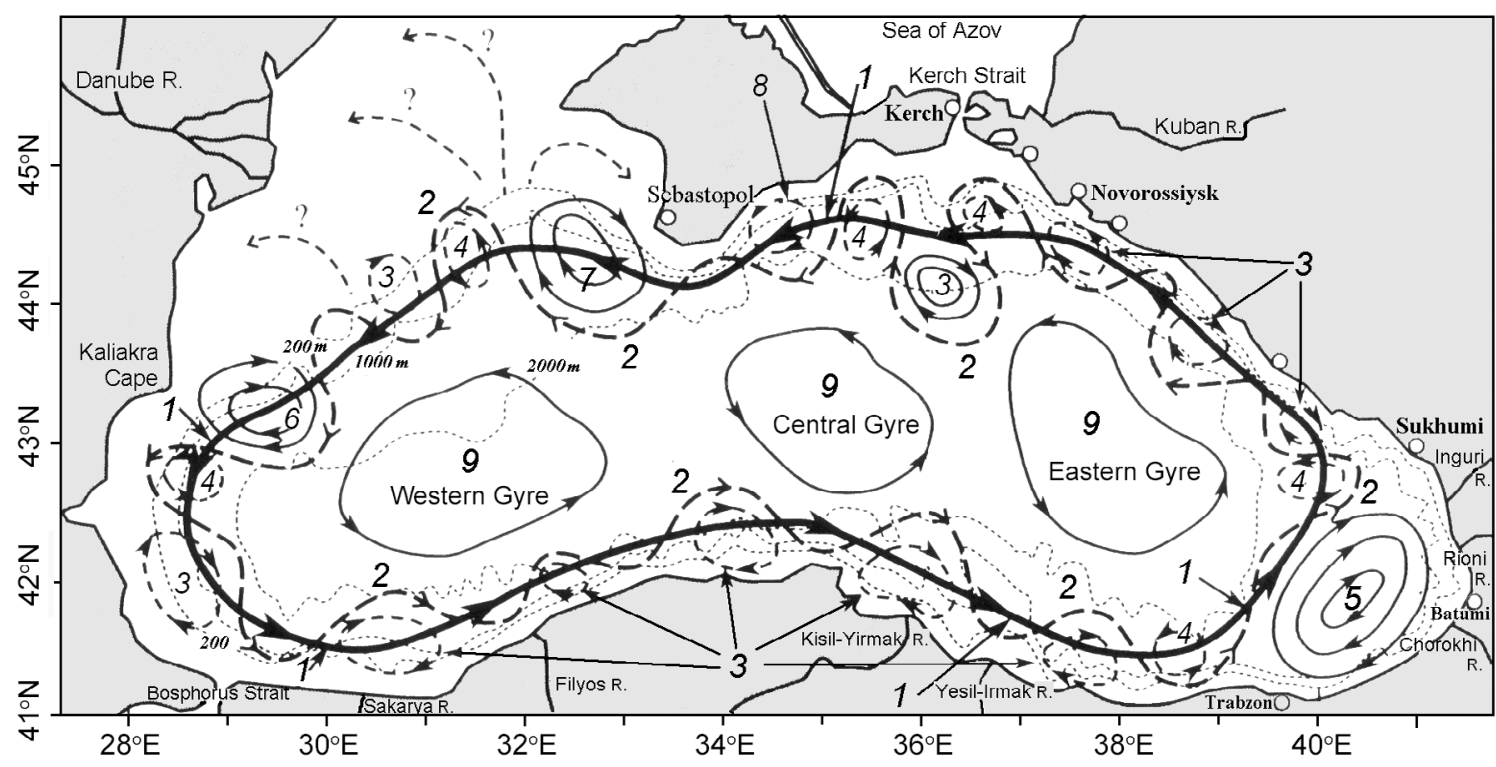

Fig. 1. Schematic of the Black Sea circulation during summer based observations (after Krivosheya et al. 2000). 1: mean position of the cyclonic Rim Current jet current; 2: Rim Current meanders; 3: anticyclonic coastal eddies (ACEs); 4: cyclonic eddies (CEs); 5: Batumi anticyclonic eddy; 6: Kaliakra anticyclonic eddy; 7: Sebastopol anticyclonic eddy; 8: Crimea anticyclonic eddy; and 9: quasi-stationary cyclonic gyres.

grazing the Romanian and Bulgarian coasts, where they are eventually absorbed back into the gyre. Unlike the Batumi eddy, the SAE is relatively unbounded in size and once shed from the peninsula, is transported as a closed vortex by the $\mathrm{RC}$ as it circulates along the continental slope towards the southwest. An analysis of eddy trajectories from satellite imagery (Ginzburg et al. 2002a) shows that the Sebastopol eddies drift to Bulgaria's Kaliakra Cape (Fig. 1) in about three months, agreeing well with DieCAST climatological predictions (Staneva et al. 2001).

Mesoscale features such as anticyclonic and cyclonic eddies, squirts and jets, all play an important role in the circulation, mixing and marine ecology of the Black Sea (BS). The aperiodic baroclinic instability of the currents and the ensuing generation of eddies, filaments, and mushroomlike currents significantly contribute to the hydrographic, hydro-biological and hydro-chemical exchanges between the near-shore zone and the open sea. Figure 2 is a SeaWiFS enhanced image of sea-surface color taken on 11 June 2000, which illustrates many of these processes.

Episodic wind forcing intensifies the vertical stirring and mixing, which significantly enhance the effect of mesoscale structures on the general dynamics and exchange, as well as the dispersion of oil plumes in the BS. For example, the Sebastopol Eddy's swirling motion accumulates contaminants from the heavily polluted northwestern region of the Sea and eventually delivers its entrained pollutant load along the Turkish coast. In addition, small ACEs aperiodically appear along the Turkish and Caucasus coasts, which can trap pollution, and subsequentially transport and deliver these contaminants to beaches far from their origin.
As it is logistically difficult to obtain synoptic oceanographic and meteorological observations in and over the Black Sea, at this early stage of development of SSBOM, a better approach is to run representative high-resolution, lowdissipation numerical simulations of mesoscale processes with DieCAST forced by climatology, coupled with the oil plume module. Various oil spill accident scenarios can then be run for a variety of locations and seasons, to build up an understanding of where the most critical sites are located and what the expected pathways and rates of dissipation of oil slicks might be. This method thus builds an atlas of generic simulations which provides the foundation for more sophisticated simulations run in an operational mode with observed winds, hydrography and river discharges.

This paper is structured as follows: In section 2, the description of the coupled circulation/particle tracking transport model is presented. In section 3, results of transport simulations for a number of injection scenarios in representative regions of the Sea over two seasons are discussed. A summary is presented in section 4 .

\section{DESCRIPTION OF THE COUPLED MODEL}

\subsection{The DieCAST Circulation Model}

A primary reference for the DieCAST ocean circulation model is Dietrich et al. (1997). For this application a $1 / 30$ deg. lateral resolution (Mercator grid), 30 vertical zlayer version was developed. This is significantly higher than the Black Sea $1 / 12^{\circ}, 20$ vertical layer version described in Staneva et al. (2001). This lower resolution model offered promising results for oil mass transport under condi- 


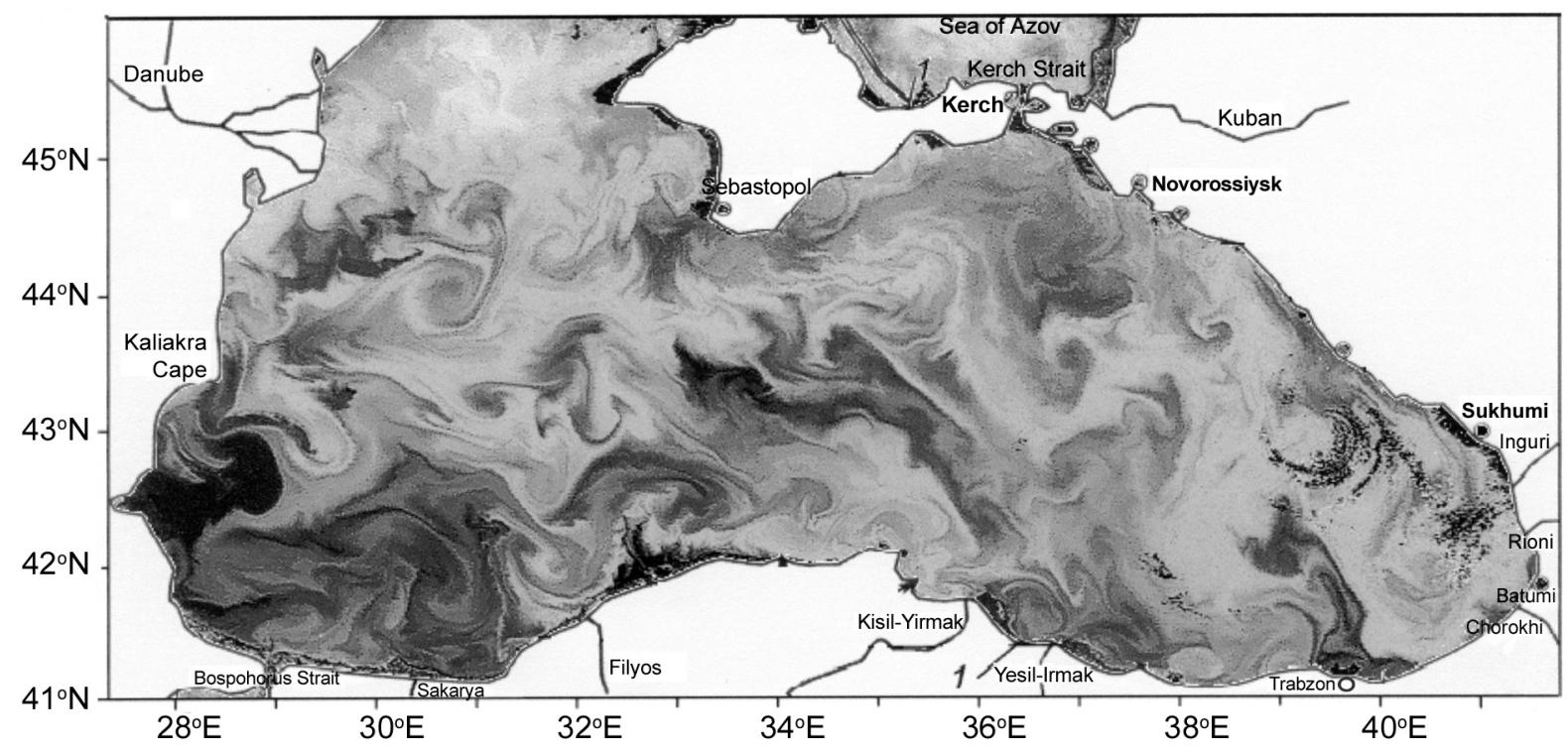

Fig. 2. Enhanced SeaWiFS sea surface color image, 11 June 2000.

tions of general Black Sea circulation, but lacked sufficient resolution to realistically reproduce details of oil plumes at the low end of the mesoscale. Basic details of the coupled DieCAST/oil spill model is described in Korotenko et al. (2003).

The present model covers the entire Black Sea basin from 27.7 to $19.6^{\circ} \mathrm{E}$ and from 40.9 to $41.8^{\circ} \mathrm{N}$, and contains a total of $426 \times 238$ rectangular grids, with 30 unevenly spaced levels in the vertical. Interfacial depths increase geometrically (rounded) at $\sim 0,3,6,10,14,18,23,29, \ldots, 1355,1645$, and $2000 \mathrm{~m}$. Maximum vertical resolution in the upper 100 $\mathrm{m}$ provides better representation of near-surface dynamics and oil dispersion processes. The integration time step for both models was 6 min. DieCAST was spun up from rest over a time $\mathrm{T} \sim 5$ years (with same wind and hydrographic data as in Staneva et al. 2001). Oil slick runs were normally run for an additional 15 days, see below.

The model has been validated by a variety of comparisons with satellite based and in situ data (e.g., Staneva et al. 2001). This validation included all known significant Black Sea general circulation characteristics needed to describe the "underlying flow" (i.e., circulation in the upper mixed layer) at a given place and time. The underlying general circulation is important, especially when oil is leaking from a shipwreck at the ocean bottom (e.g., the Prestige oil spill disaster). The underlying flow does not include:

(a) fast barotropic mode surface gravity waves which have little effect on oil material displacement unless they break in the region containing oil material, which happens only in the shallow littoral regions and requires specialized subgridscale parameterization and ultra-high resolution; (b) the surface mixed layer, which has a fast time scale response to wind events lasting at most a few days. It is easily validated separately; and is only weakly coupled to the underlying general circulation currents that are little affected by major storm events, responding mainly to much longer time scale wind forcing (that is, having time scales $>>5$ days).

The model uses no data assimilation, so the good comparison with a wide variety of observations shown by Staneva et al. (2001) demonstrates the dynamic similarity of the model simulated Black Sea general circulation to the observed Black Sea general circulation, as will be required for oil spill response applications.

Cushman-Roisin et al. (2007) and Cushman-Roisin and Korotenko (2007) report on apparently realistic DieCAST simulations in the Adriatic Sea where the grid size was significantly less than the first internal baroclinic deformation radius $R$ to adequately resolve coastal mesoscale structures and their variability (for the Black Sea $R \sim 5-20 \mathrm{~km}$, depending on location and season).

The model was initialized with January-averaged temperature and salinity data and forced with climatological winds and surface buoyancy (heat) fluxes, evaporation minus precipitation and with river runoff from 31 rivers (Jaoshvily 2003). The discharges from each of the 10 major river sources are varied as monthly climatological means derived from gauged discharges (Jaoshvily 2003). Twolayered exchange through the Bosphorus is specified to maintain conservation of water and salt (Staneva et al. 2001). Note that the climatological data provided from the CoMSBlack surveys have been prepared in the context of the NATO Black Sea project (cf. Staneva et al. 2001) and 
river discharges were specified from Jaoshvily (2003).

The DieCAST model reproduces fundamental physical features of the Black Sea: seasonal fluctuations in the quasipermanent cyclonic Rim Current, Rossby waves propagating westward across the basin, coastally trapped waves, and the annual cycle of vertical mixing (Staneva 2001). Due to high resolution and extremely low horizontal dissipation (5 $10 \mathrm{~m}^{2} \mathrm{~s}^{-1}$ ), the model reproduces numerous mesoscale structures: cyclonic eddies and meanders lying between the Rim Current and open sea, anticyclonic meanders and eddies lying between the Rim Current and the coast, mushroom-like instabilities, jets and filaments. The low dissipation allows mesoscale instabilities to develop at length scales of 5 $20 \mathrm{~km}$ and over time scales of a few days.

The main features of basin and mesoscale circulations predicted by DieCAST have been compared with NOAA satellite images of sea surface temperature (Ginsburg et al. 2002a, b), and derived surface current velocities obtained from observations (Oguz et al. 1994; Krivosheya et al. 2003) and drifter experiments (Zatsepin et al. 2003; Zhurbas et al. 2004).

\subsection{The Oil Spill Model}

The SSBOM uses the same $426 \times 238$ grid as DieCAST. The vertical resolution is uniform at $0.1 \mathrm{~m}$ over the upper $100 \mathrm{~m}$ for a total of 1000 layers. Oil sinking below that depth is lost to the system. Once oil is discharged onto the sea surface, many factors affect its properties, transport and dispersal. Processes of evaporation, emulsification, dissolution, photolysis, and biodegradation are controlled by properties of the oil itself (Wheeler 1978). Different processes sequentially dominate as the plume evolves over time following the spill, eventually lead to a complete loss of the oil mass. The relative importance over time, of the various processes active on the mass of an oil spill, is sketched in Fig. 3. For example, evaporation, dispersion, and emulsification are important in the early stages, while biodegradation, photolysis, sinking, and tar-ball formation become important later over a period of days and months and even years (Wheeler 1978). Depending on the grade of the oil, the relative effects of photolysis and biodegradation to the mass balance may be small in comparison with the evaporation, dispersion, and emulsification processes.

Special attention is paid to advection processes that act over all phases of the slick dispersion process. Advective transport is accounted for by following the movement of the centroid of the oil slick by the seasonal circulation buoyancy-driven and wind-induced currents. In the most general case, advection due to the combination of these components is described by their vector sum

$$
V_{i}=V_{i}^{\text {wid }}+V_{i}^{\text {wad }}+V_{i}^{d}+V_{i}^{c}+V_{i}^{B}
$$

where $V_{i}^{\text {wid }}$ and $V_{i}^{\text {wad }}$ correspond to velocity due to wind drift and wave (Stokes) drift component, respectively which, generally, do not coincide in direction; $V_{i}^{d}$ is the time average velocity of the wind-induced component, $V_{i}^{c}$ denotes the climatological average component, and $V_{i}^{B}$ is the buoyancy driven component. Following (Elliott 1986), for the sum of the wind-induced and Stokes drift components, $V_{i}^{\text {wid }}+V_{i}^{\text {wad }}$ we express in terms of the wind speed $U_{A}$ at $10 \mathrm{~m}$ above the water surface as $V_{i}^{\text {wid }}+V_{i}^{\text {wad }}=0.03 U_{A}$. Gravitational spreading generally plays a dominant role in the first few hours following the spill. In the present version of the SSBOM model spreading is treated as a sub grid process and is not resolved (Korotenko et al. 2001, 2002).

The basic concept of the oil transport and dispersal model is similar to that presented in Korotenko et al. (2003), in which oil is initially divided into fractional hydrocarbon groups in order to describe the evaporation process with more accuracy (Mackay and McAuliffe 1988). The hydrocarbon groups $\mathrm{C}_{1}-\mathrm{C}_{8}$ were chosen for typical crude oil (Korotenko et al. 2001, 2004).

The procedure of predicting oil spill behavior is divided into two parts: i) predetermination of surface and vertical currents, temperature and salinity with the DieCAST hydrodynamic model; and ii) applying these three-dimensional motions to the behavior of individual oil droplets, the aggregate of which constitutes the oil plume. The model thus simulates the advection, turbulent diffusion and physicochemical decay processes that change the oil plume's structure and properties. Emulsification is modeled on the approach suggested by Fingas and Mullin (1999) which describes the process of formation of "water-in-oil" mousse.

In the random walk approach used, the displacements of each oil droplet are estimated as (Korotenko et al. 2003):

$$
\begin{aligned}
\left(\Delta x_{i}\right)_{j, k}= & V_{i, j} \Delta t_{j}+\left(\eta_{i}\right)_{j, k} \\
& \left(i=1-3 ; j=1,2, \ldots N_{i} ;\right. \\
& \left.k_{f}=1,2, \ldots, N_{f} ; f=1,2, \ldots, 8\right)
\end{aligned}
$$

In Eq. (2), the displacements $\left(\Delta x_{i}\right)_{j, k}$ are defined as the deterministic part of the motion due to the mean velocity field, $V_{i, j}$ and the random displacement, $\left(\eta_{i}\right)_{j, k}$ is due to velocity fluctuations and denotes the displacement of the $k$-th particle moving along the $x_{i}$ - axis at the $j$-th instant of time, $N_{t}$ is the total number of time steps, $\Delta t$ is the time step, $N_{f}$ is the number of particles in each fraction, and the subscript $f$ denotes a particle fraction.

The distribution of the number of particles in fractions is based on eight hydrocarbon groups; initially assigned and distributed randomly depending on the type of oil. The total number of the particles launched in the model usually does not exceed $10^{7}$; nevertheless, the behavior of the tracked particles proved to be representative of the entire spill, even 


\begin{tabular}{|l|l|}
\hline EISPERSION (OiI Drops Formation) \\
\hline EMUL SIFICATION 'Water-in-Oil' \\
\hline RIODEGRAPION (photo-oxidation) \\
\hline DISSOLUTION \\
\hline SINKINGISEDIMENTATION \\
\hline TAR-BALL FORMATION \\
\hline
\end{tabular}

Fig. 3. Schematic representation of the relative importance of spill processes over elapsed time (modified from Wheeler 1978).

though each droplet represents only an infinitesimal part of the total oil volume. Within each fraction, each droplet is also randomly distributed to have its own half-life according to empirical exponential laws (Yang and Wang 1977).

At the moment of each injection of particles (for a continuous release), the distribution of their "half-life" in fractions/hydrocarbon groups is assigned randomly by a random number generator. The generator gives uniform choices distributed uniformly between 0 and 1 . The initial uniform distribution is transformed into an exponential distribution with a weight dependent on current wind speed magnitude at the sea surface and oil temperature (see Mackay and Matsugu 1973). This approach is very important for realistic modeling of evaporation processes. The "long-living" oil fractions are randomly and exponentially distributed within a range corresponding to the slow effects of total degradation, typically $\sim 250$ hr "half-life" (Korotenko et al. 2003).

In addition to the deterministic movements due to mean current velocity, oil droplets experience a random diffusion due to velocity fluctuations, the distribution law of which is represented by the term, $\left(\eta_{i}\right)_{j, k}$, generally a function of time and space. The character of $\left(\eta_{i}\right)_{j, k}$ is determined by the statistical structure of the velocity fluctuations around its mean value at each time step $\Delta t$. Since these fluctuations are considered independent, the law for $\left(\eta_{i}\right)_{i, k}$ is considered to be Gaussian (Monin and Yaglom 1965). In this case, the $\left(\eta_{i}\right)_{j, k}$ can be represented as $\left(\eta_{i}\right)_{j, k}=\gamma_{j, k}\left(2 K_{i, j} \Delta t\right)^{1 / 2}$, where $\gamma_{j, k}$ is a random vector normally distributed with an averaged value of zero and unit standard deviation; $K_{i, j}$ represents coefficients of diffusion along the $x_{i}$ - axis at the time $t_{j}=t_{0}+j \Delta t$. The random vector, $\gamma_{j, k}$, is obtained with the use of the random number generator, giving a homogeneous distribution of random numbers between 0 and 1 , with consequent transformation to the Gaussian law.
The horizontal and vertical diffusion coefficients, $K_{x, j}$, $K_{y, j}$, and $K_{z, j}$, are calculated with a special turbulence submodel incorporated into SSBOM, while the mean current velocity $U_{i}^{j}$ and density $\rho$ are provided by the DieCAST circulation model. The turbulence sub-model is developed on the base of the $k-\varepsilon-\tau$ turbulence model and described in detail by Korotenko (1992).

In addition to diffusion, oil is vertically dispersed in the water column by wind-generated breaking waves. In high seas when a slick is subject to continual turbulent stirring by wind shear and breaking waves, the oil may be rapidly dispersed into small drops 0.01 to $1.0 \mathrm{~mm}$ in diameter, which populate the subsurface layers. One common approach employed to describe this process is based on tabulations of dispersion as a function of sea state and elapsed time after oil release (Audunson 1979).

The natural dispersion process is very complicated and the exact nature of the fluid mechanics involved is not well understood. The most common supposition is that breaking waves or turbulence causes the oil layer to be propelled into the water column thus forming a "shower" of oil droplets. Most of the oil particles rise again to the slick and coalesce there, but some of the smaller droplets diffuse downward and become permanently incorporated into the water layer. This makes the process of oil transport in the sea essentially three-dimensional with in-situ measurements detecting oil droplets down to $20 \mathrm{~m}$ (Genders 1988).

As was shown by Aravamudan et al. (1982), the dispersion rate is a function of the oil slick thickness, oil-water interfacial tension, sea state, and, in particular, the fraction of the sea which is covered by breaking waves. According to a series of laboratory investigations on the natural dispersion of oil on the surface and in the water column, a surface oil slick breaks up into droplets and penetrates into the water under the action of the turbulence generated by breaking waves. Then, the turbulence in the ambient water breaks up the submerged oil parcels into droplets. Hence, the dispersion process due to the turbulence might be treated as the result of a continuous surface source supplying oil droplets with different sizes.

According to laboratory experiments by Delvigne (1993), the dispersed mass of oil droplets per unit surface rate and per dispersion event $M(d)\left[\mathrm{kg} \mathrm{m}^{-2}\right]$, is given by

$M(d)=C(0) D_{B A}^{0.57} S_{c o v} d^{0.7} \Delta d$

where $C(0)$ is a proportionality constant dependent on the temperature and viscosity of oil, $D_{B A}=0.0034 \rho g H_{r, m . s .}^{2}$ is the average energy dissipation per unit surface area in a overturning wave, $H_{r . m . s .}$ is the r.m.s. value of the wave height in the wave field, $S_{c o v}$ is the fraction the sea surface covered by oil, $g$ is the acceleration due to gravity, and $\rho$ is the density and $v$ the viscosity of water. The droplet diam- 
eter, $\Delta d$, in the experiments was found to lie in the range of to $1130 \mu \mathrm{m}$, with most of the droplets were concentrated in the range between 75 and $320 \mu \mathrm{m}$ with a slight tendency for the median of the droplet size distribution to shift to smaller sizes with increasing turbulence duration.

In the SSBOM model, the particles' diameters, $d$ are assigned randomly in the range $\left(d_{\max }-d_{\min }\right)$, where $d_{\min }$ and $d_{\max }$ are minimum and maximum diameters of oil droplets. The critical diameter, $d_{c}$, (Aravamudan et al. 1982) is given by the expression $d_{c}=\frac{9.52 v^{2 / 3}}{g^{2 / 3}\left(1-\rho_{0} / \rho\right)^{1 / 3}}$, where $\rho_{0}$ is density of oil droplets, $v$ is viscosity of ambient water. The buoyancy force depends on $\rho_{0}$ and size, $d$ of the droplets and the vertical sinking velocity, $w$. The latter, according to Proctor et al. (1994), can be estimated as $w=\frac{g d^{2}\left(1-\rho_{0} / \rho\right)}{18 v}$ for small droplets $d \leq d_{c}$, and as $w=\left[\frac{8}{3} g d\left(1-\rho_{0} / \rho\right)\right]^{1 / 2}$ for large droplets $d>d_{c}$. Hence, the larger droplet sizes are more buoyant and tend to remain near the sea surface, while the smaller droplets are less buoyant and may be transported downward due to turbulence and vertical convection at, for example, fronts.

Each particle, droplet $k$ belonging to fraction $f$ is characterized by its size, density, position $X_{i, j}^{k}$, age and its own "half-life", the latter being assigned a priori when the par- ticle is launched.

Algorithms for evaporation, emulsification and decomposition (the latter due to biochemical and physical degradation) are incorporated in an ancillary sub-model; they are parameterized in terms of "half-life" time filters, which compare current time and the "half-life" time assigned for each particle. Only particles that occur within the subsurface "evaporation layer" of thickness, $z_{e v} \sim 0.1 \mathrm{~m}$, experience evaporative decay, while particles at all depths in the water column experience disintegration and dispersion due to ambient turbulence.

In the SSBOM, counting algorithms are used to determine the number of oil droplets that are deposited into sediments or beached. Should a droplet reach the coastline or bottom, it is marked as deposited or beached; its coordinates are fixed at the point where the droplet reached that boundary. This procedure accounts for the redistribution of the total oil mass in different part: oil evaporated, oil beached and oil deposited that obviously very important for an assessment of the risks of coastline contamination (Korotenko et al. 2002, 2004).

Operationally, the coupled model is controlled primarily through the "Oil Spill Model" graphical user interface (GUI) dialog with a map of the Black Sea (Fig. 4). The model is started with "Update and Run" button, which ingests bathymetry, DieCAST-predetermined current velocities,

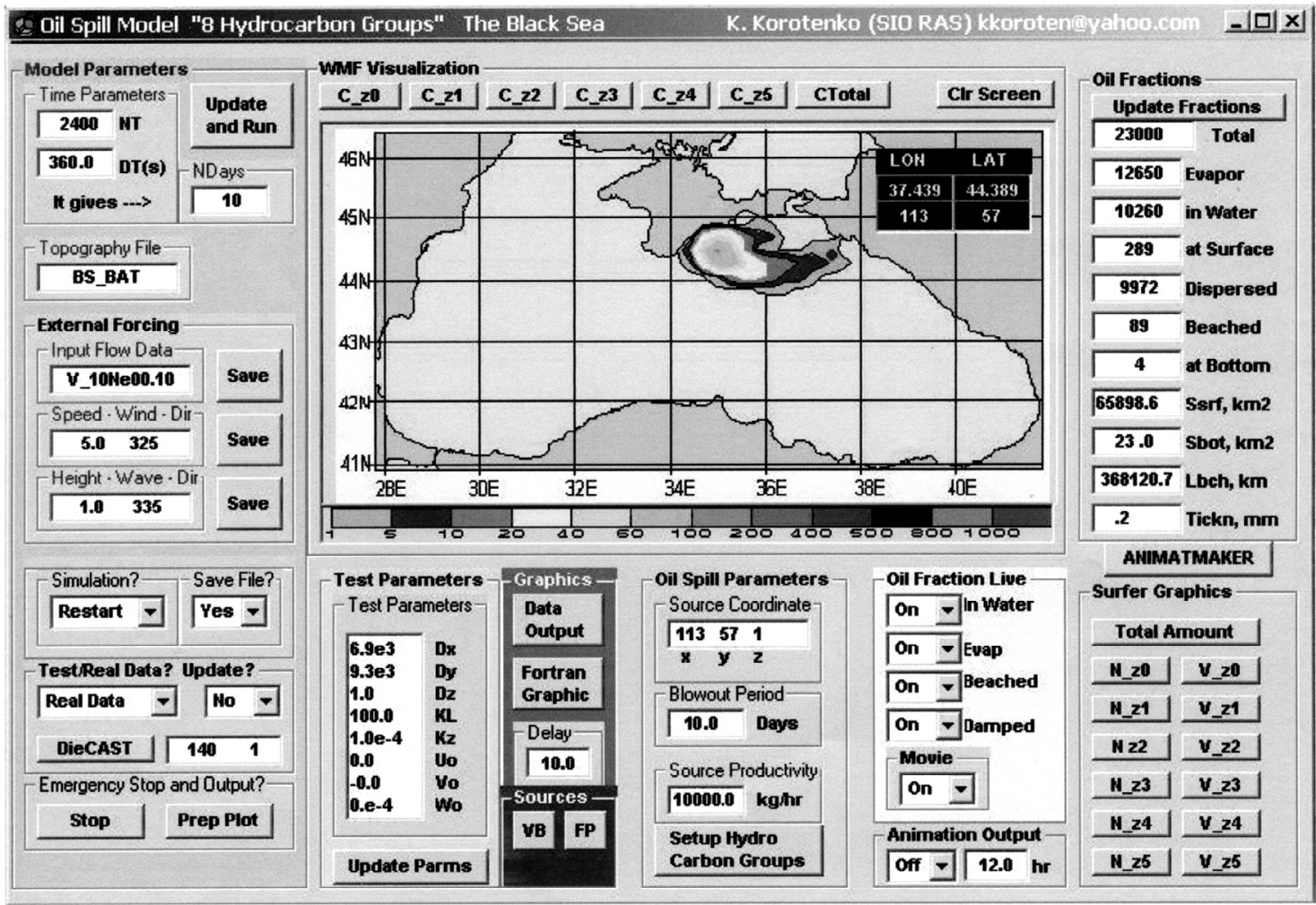

Fig. 4. Graphical User Interface (GUI) of the Shirshov-Stony Brook Oil spill transport Model (SSBOM). A detailed description of user defined controls and variables is Korotenko (2002). 
and various model and source parameters. A source position is pre-assigned by the mouse pointer location; in doing so the latitude and longitude coordinates and depth will be displayed. The operator may choose whether the spill is instantaneous or continuous, specifying the blowout period.

Once the model is running, the user may also specify current wind and wave and other external and forcing conditions as well as components of oil mass balance, i.e., oil evaporated, oil beached, oil deposited, etc. could be displaied during the calculations. Using the GUI, it is possible to switch between direct wind forcing of the plume via a linear wind stress formulation as described in section 2.2, or indirectly through the upper layer velocities of DieCAST. Also, Stokes' drift can be switched on and off depending on wave conditions. It should be noted that once the "Update and Run" button is clicked, it runs a separate graphic window which displays real-time motion of particles. The concentration of oil recalculated from particle density and oil fraction distributions during the spilling and dispersing process are displayed on the map and in corresponding frames at the upper right corner of the GUI. A second GUI, which appears by clicking "Setup Hydrocarbon Groups" button, allows the user to input the type and known properties of oil.

\section{RESULTS}

\subsection{Modeling the Black Sea Circulation at High Resolu- tion}

The high resolution DieCAST simulations of velocity, temperature and salinity confirm that the Black Sea circulation is dominated by meanders, eddies, filaments and di- pole structures with scales comparable to those found during ocean surveys (e.g., Oguz et al. 1994; Krivosheya et al. 2000) and from analysis of satellite images (e.g., Ginzburg et al. 2002a, b; Zatsepin et al. 2003; this paper). The model faithfully produces about twelve coastal anticyclonic mesoscale eddies during an annual run (Fig. 5) and predicts the general characteristics and seasonal variability of the major mesoscale structures: Rim Current meandering, generation of coastal anticyclonic and cyclonic eddies including Sebastopol, Kerch and Batumi eddies.

In accordance with the observations (e.g., Krivosheya et al. 2000) our numerical experiments show that during the warmer months of April through October, the intensity of the $\mathrm{RC}$ 's meandering is greater than in the winter period. It is this intense meandering that triggers the anticyclogenesis of ACEs. During the winter months, surface cooling decreases the vertical stratification, but has less effect on horizontal buoyancy gradients, which are controlled mainly by the entrainment of river water into the coastal currents. Figure 5 is a surface velocity snapshot for Julian Day 10 (January 10), indicating that the high-resolution DieCAST model resolves the important mesoscale features of the Black Sea circulation. The weakly stratified winter environment favors the generation of anticyclonic headland wake eddies, such as the Sebastopol eddy to the west of the Crimean Peninsula (Fig. 5).

Numbers $1-9$, identifying major features, are inserted in Figs. 1 and 5 for comparison. Plots of sea surface temperatures (SSTs) for climatic January and July are presented in Figs. 6a and b, respectively, using a banded grayscale palette to better sharply define meso-structures. The Sebas-

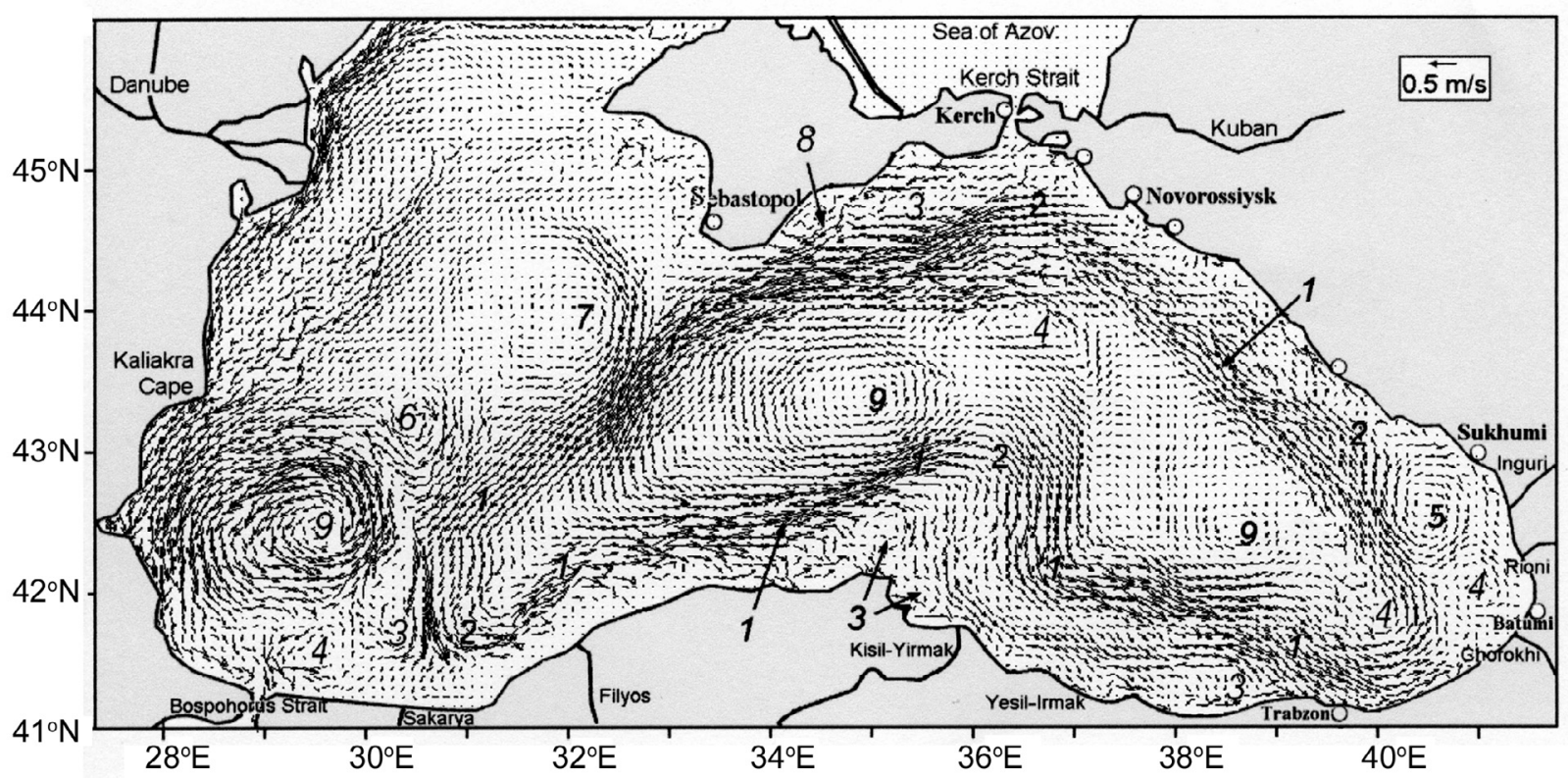

Fig. 5. Snapshot pattern of the sea surface circulation forced by climatic January winds. The numbers identify several significant circulation patterns shown in Fig. 1. 
topol (7) and Batumi eddies (5) are clearly identified for January, while for July a greater instability is apparent in the Rim Current and the generation of ACEs along the Turkish and Caucasus coasts. A comparison of Figs. 2 and $6 \mathrm{~b}$ shows a number of identical mesoscale structures such as ACEs along the Caucasus and Turkish coasts, chaotic filaments and mushroom currents located along the Romanian and Bulgarian coasts. It is interesting that both panels show that the $\mathrm{SAE}$ and the BAE are absent during the spring-summer period. Note that in Figs. 5 and 6a a dipole structure associated with the BAE is evident, accompanied by an adjacent smaller cyclonic eddy (marked by "4" in Fig. 5). DieCAST is the first circulation model to resolve these features in this area.

As the modeling shows, the genesis and evolution of the BAE typically has three phases: i) it initially appears as an instability of the meandering Rim Current west of Trabzon, Turkey (Figs. 2 and 5), and propagates as a small ACE moving eastward along the Turkish coast; ii) the BAE grows in size and strength as it travels to the easternmost part of the sea where the distance between the RC and the Georgian coast is a maximum; iii) the dissipation (senescent) phase typically occurs in the region to the north of Sukhumi (Figs. 1 and 5) where the BAE is absorbed back into the RC.

The life span of the BAE is $\sim 3.5$ months (both observed and modeled), usually existing from November through February (Ginsburg et al. 2002a). A cyclonic eddy following the demise of the BAE usually appears during the second phase but subsequentially dissipates several weeks after the BAE has dissipated.

Coastal cyclonic eddies are rare, but when they occasionally occur, they are critical for the health of the local environment since due to surface divergence, they enhance the self-depuration processes in highly polluted coastal zones (I. Ovchinnikov, priv. comm.).

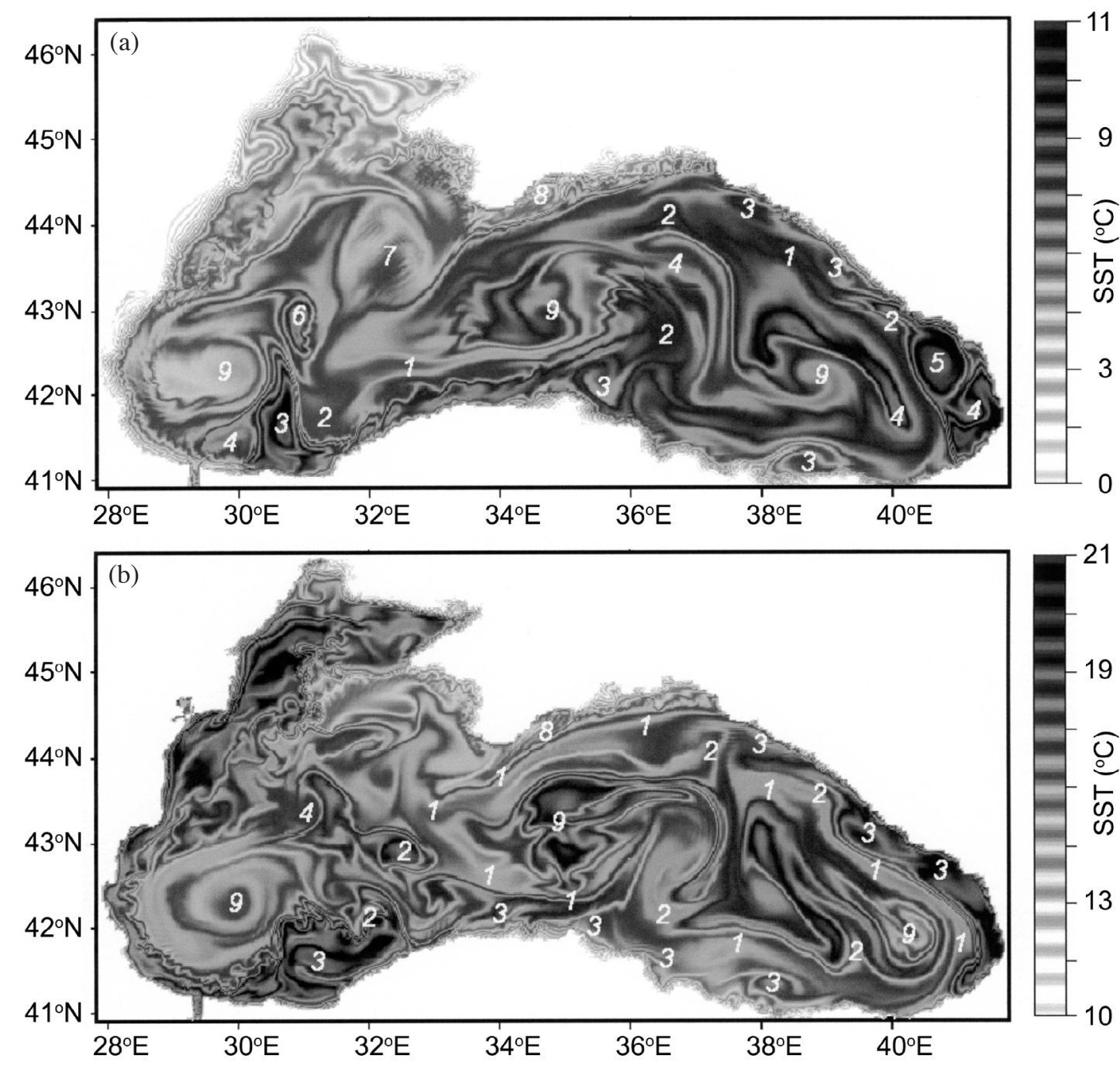

Fig. 6. Plot of sea surface temperature for (a) climatic January forcing; (b) climatic July forcing. The numbers identify several significant circulation features shown in Fig. 1. 
Incidentally, the previous coarser 5-min version of DieCAST (Staneva et al. 2001; Korotenko et al. 2003) was unable to resolve fine dipole structures formed in the narrow area between the Georgian coast and the RC. Observations in the region of the Batumi eddy show that currents at various times can change their sign of rotation from cyclonic to anticyclonic (Staneva et al. 2001).

\subsection{Modeling Oil Spills from Hypothetical Accidents}

As a preliminary step towards a comprehensive atlas of characteristic oil spill trajectories in the Black Sea, several scenarios were chosen with four hypothetical accidental oil releases which might occur along heavily-trafficked shipping routes between the ports of Novorossiysk and the Bosphorus Strait (see Fig. 1 and "Source Locations" in the insert in Fig. 7, Site 1), especially as the transportation of oil may pose serious hazards to the beaches of Russia, Ukraine and Turkey.

To contrast seasonal effects, the experiments were performed for climatological conditions found in January and July. Ten-day blowouts, each releasing 240 tons of oil per day were chosen as representative, with the computations performed over 15 days, i.e., finishing 5 days after the oil spill ceased. In the experiments, during the period of the blowout 1000 particles were released at each time step, $\Delta t=6 \mathrm{~min}$, for a total number of particles $\sim 2.4 \cdot 10^{6}$ so that each launched particle "carries" $1 \mathrm{~kg}$ of oil. Since such a size and weight of oil droplets are hugely unrealistic, it is assumed that such a "macro" particle will represent a cluster of droplets with a size that is randomly chosen for this "macro" particle at the moment of its release, within the range $\left(d_{m i n}\right.$, $d_{\max }$. This approach is computationally efficient.

In the oil spill experiments, oil characteristics (light crude) were chosen as follows:

- oil density $=872 \mathrm{~kg} \mathrm{~m}^{-3}$;

- droplet diameters: $d_{\min }=60 \mu \mathrm{m}$ and $d_{\max }=600 \mu \mathrm{m}$; - evaporation times, and "half-life": $T_{e v 1}=20 \mathrm{hr}, T_{e v 3}=30 \mathrm{hr}$, $T_{e v 5}=10 \mathrm{hr}$, for the fractions $\mathrm{C}_{1}, \mathrm{C}_{3}$, and $\mathrm{C}_{5}$, respectively. For the "longer-lived" fractions, $\mathrm{C}_{2}, \mathrm{C}_{4}, \mathrm{C}_{6}, \mathrm{C}_{7}$, and $\mathrm{C}_{8}, T_{e v 4}$ $=250 \mathrm{hr}$. The percentage ratio between the $\mathrm{C}$ fractions, established as the initial condition for the distribution of droplets was: $15 \%$ of $\mathrm{C}_{1}, \mathrm{C}_{2}$, and $\mathrm{C}_{8}, 20 \%$ of $\mathrm{C}_{3}$ and $\mathrm{C}_{4}, 5 \%$ of $\mathrm{C}_{5}, 3 \%$ of $\mathrm{C}_{6}$ and $7 \%$ of $\mathrm{C}_{7}$.

Test computations showed that $40 \%$ of such the oil evaporated within the first 5 days.

\subsubsection{Results for Climatic January}

Figure 7 depicts the distribution of the oil plume residual (concentration integrated through the water column) remaining 15 days after release for sites $1-4$. Site 1 is situated within the RC which is intensified during winter. The oil plume has an elongated form with its leading edge stretching to $31.5^{\circ} \mathrm{E}$. Meandering of the $\mathrm{RC}$ produces patchiness in the plume which was analytically described by Korotenko (1988). This scenario presents a hazardous situation mainly for the Russian and Ukrainian coasts. By day 15, over 30 tons of oil has washed up on Ukrainian beaches (see Fig. 8, Site 1).

For Site 2, coinciding with the central cyclonic gyre (locations \#9 in Figs. 1 and 5), the shape of the oil spill has an almost a circular form. Concentrations in the center of the spill are relatively higher than those for site 1 . Since the cyclonic center of the RC is a quasi-isolated structure, the oil spill remains trapped by it. In this case the oil has no opportunity to pollute the coastline.

Site 3 is situated close to the southern side of the western cyclonic gyre of the RC. The patch remains geographically isolated, with a tongue penetrating eastward. Despite the proximity of the Turkish coast, the oil seems unlikely to be beached.

Site 4 is situated in the proximity of the Bosphorus Strait on the Turkish coast. The oil slick has an irregular form. The plume spreads toward the northeast until it encounters the RC and the western cyclonic gyre. Then the leading edge of the plume splits into two branches. Despite the proximity of the Site 4 to the Turkish coast not much oil is expected to be delivered to the shoreline, with 20 tons predicted to be washed up onto the beaches.

\subsubsection{Results for Climatic July}

Figure 8 depicts a similar set of circumstances for the oil residue remaining 15 days after release from sites 1 - 4 for climatic July. The left upper panel of Fig. 8 demonstrates the final stages of the plume of oil released at Site 1. The length and surface area of the plume is shorter than that for the winter period. Weakening winds during spring and summer cause instabilities and meandering of the RC. Intensive generation of ACEs in this period arrest the spread of oil slicks as compared to winter conditions, with a possibility of entrainment into the Kerch Strait (Figs. 1 and 5).

Oil released at Site 2 is again trapped by the central anticyclonic gyre, which keeps the concentration high in the center of the plume. At the northern periphery of the plume, some oil is entrained into the RC and transported eastward.

Releases at sites 3 and 4 are likely to represent serious environment hazards for a considerable length of the Turkish coast as the plume is stretched in the direction of the RC. The simulations predict that $\sim 20$ and 10 tons of oil could be beached in the first and second cases respectively.

Figure 9 shows how an oil spill released into a developing Sebastopol eddy swirls around the intense vortex (location \#7 in Figs. 1 and 5). In this experiment, a continuous point source was placed in the center of the SAE at an epoch when it has recently separated from the western 
Crimean peninsula. Most of the released oil fractions remain inside the eddy, even after 15 days. As the eddy migrates in a southeasterly direction, it creates a perfect vehicle for the transport of contaminates.

Figure 10 demonstrates how the model typically partitions the oil mass over time: those fractions respectively
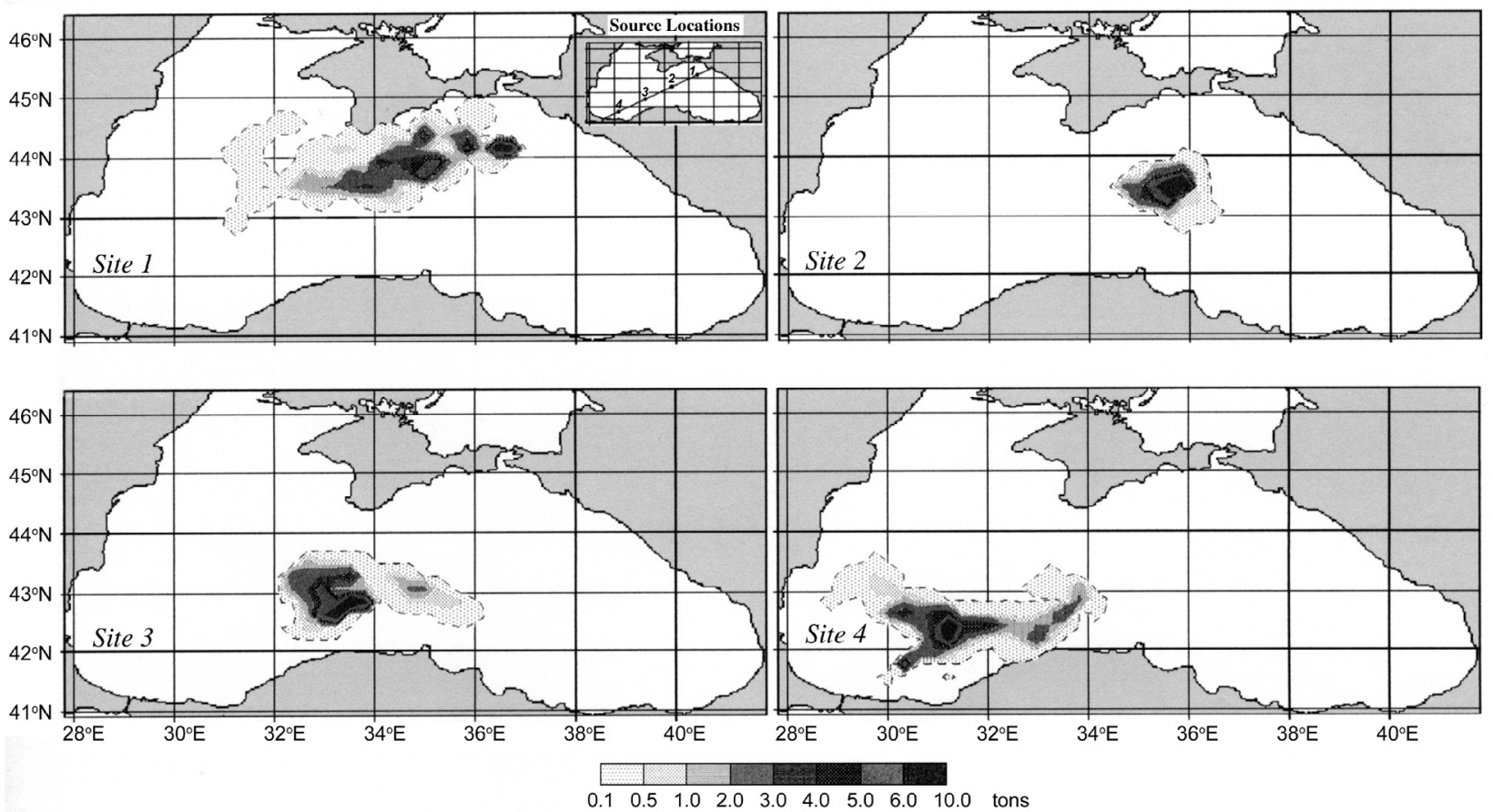

Fig. 7. Oil spill plumes for four experimental release sites during winter circulation. Oil concentrations are based on the vertical integration of oil particles over the upper $100 \mathrm{~m}$. The inset for Site 1 demarks the busy shipping lane between the Russian oil port of Novorossiysk (busiest port in the Black Sea) and the Bosporus Strait.
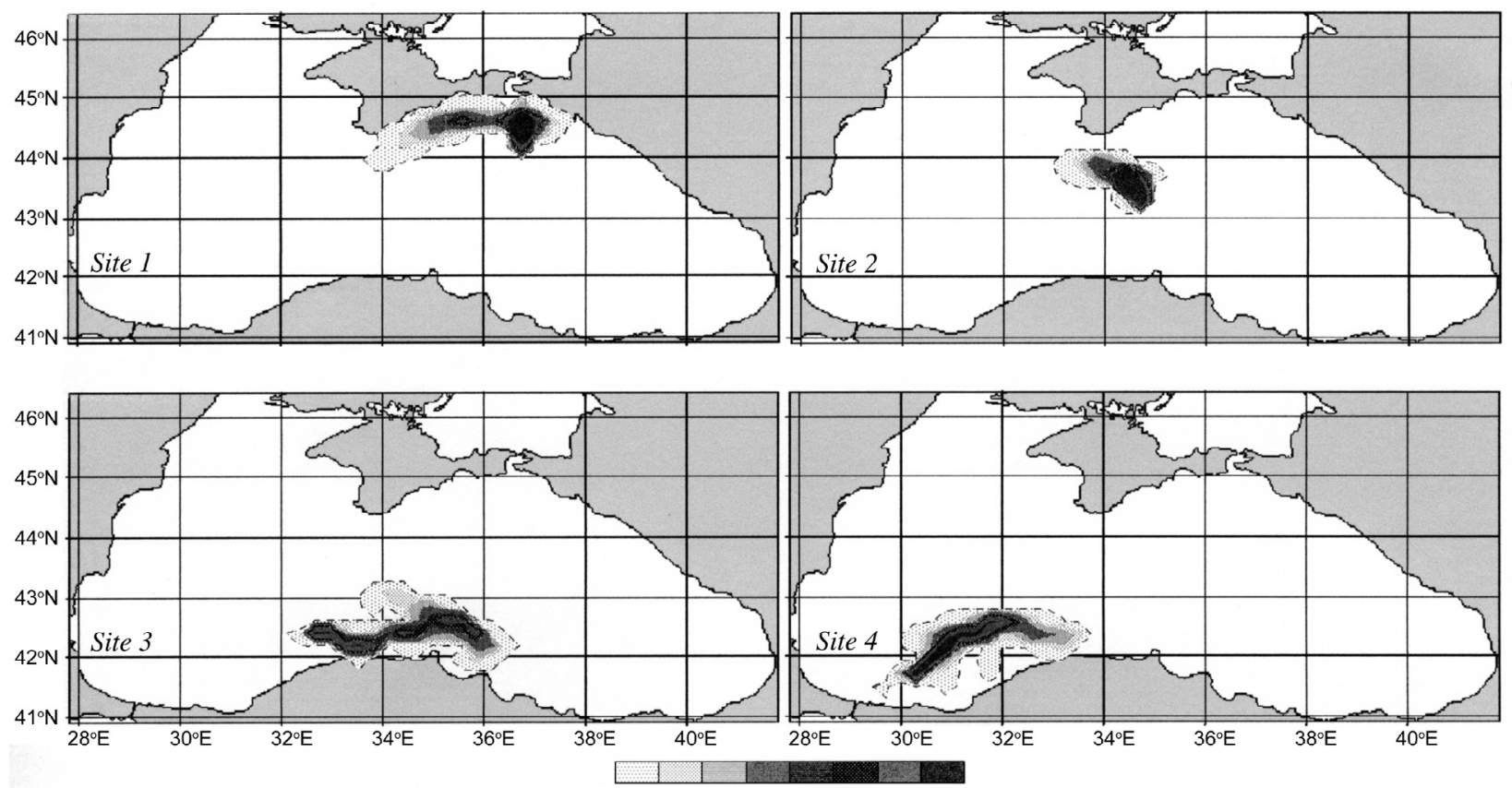

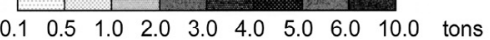

Fig. 8. Oil spill plumes for four experimental release sites during summer circulation. Oil concentrations are based on the vertical integration of oil particles over the upper $100 \mathrm{~m}$. 


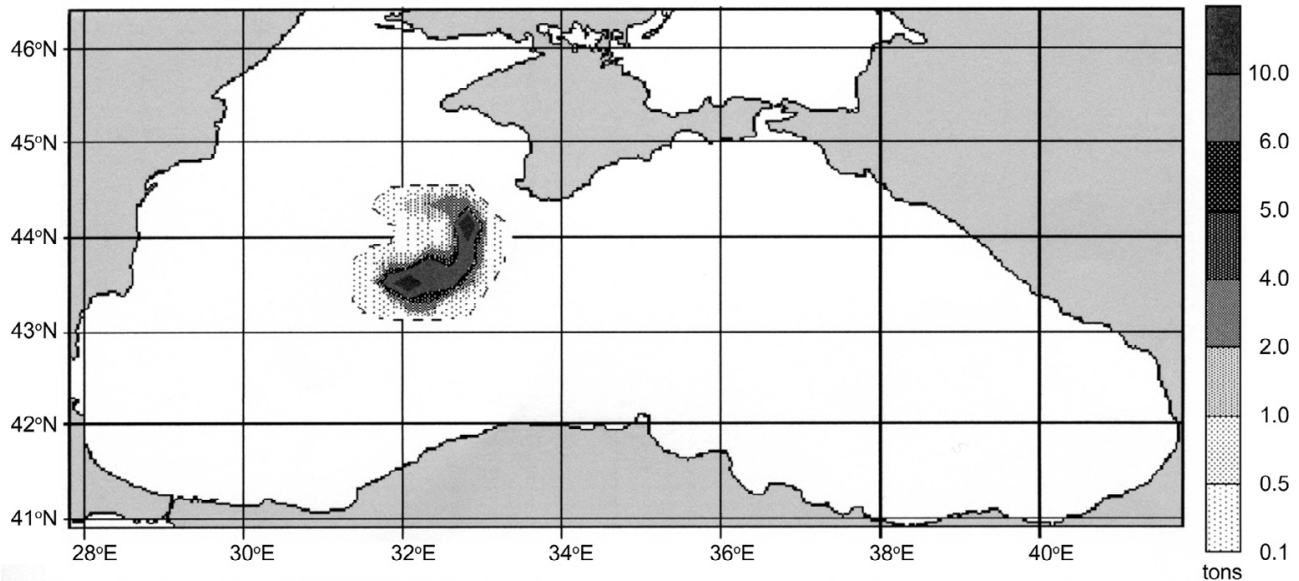

Fig. 9. Swirling oil plume resulting from a continuous point source positioned in the center of the Sebastopol anticyclonic eddy (see Fig. 1). Most of the released oil fractions remain inside the eddy, even after 15 days of discharge. As the eddy migrates in a southeasterly direction, it maintains high concentrations of oil residue within its closed surface convergence.

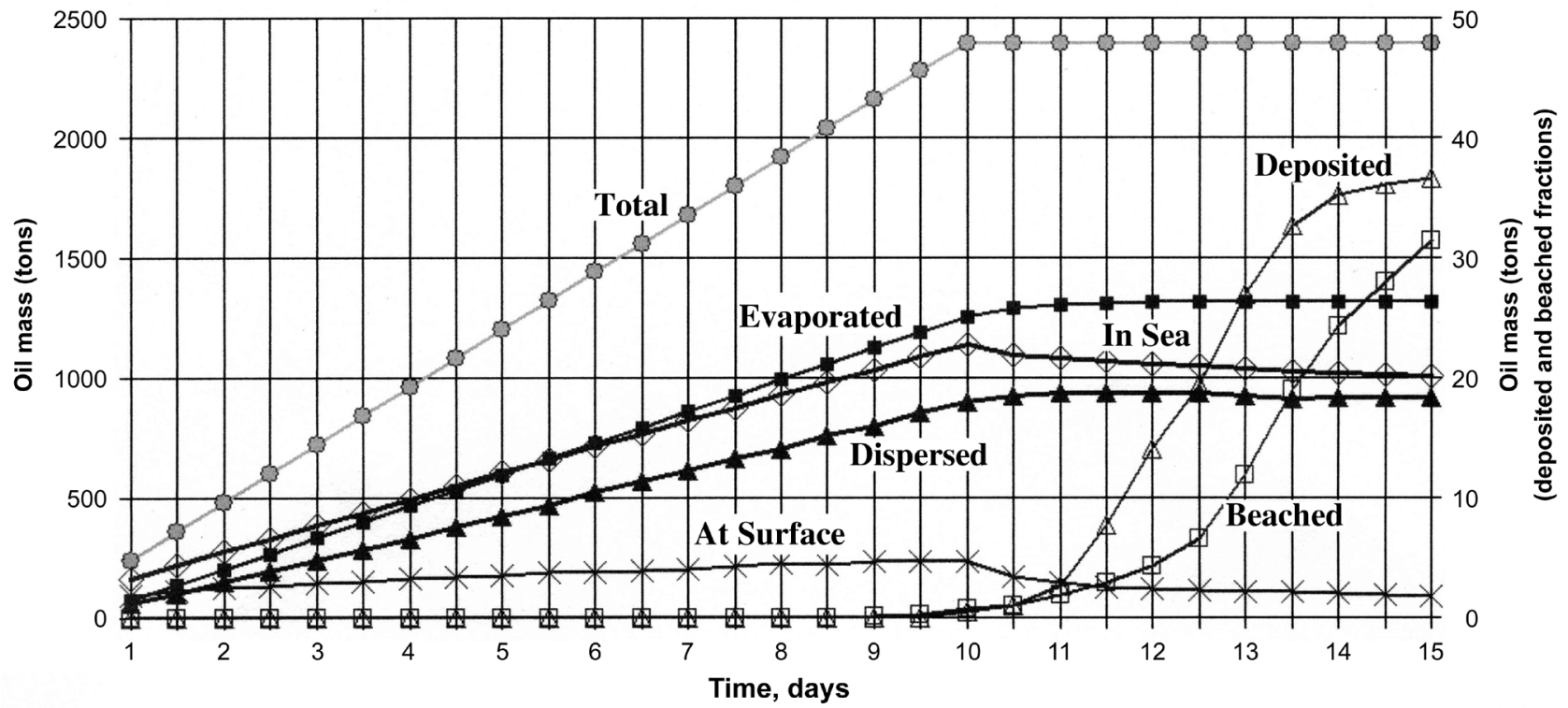

Fig. 10. Varying oil mass balance components in a typical aging oil plume. The plume fractions are evaporated, dispersed within the water column, suspended at the sea surface, deposited on the bottom and discharged on to the coastline (beached). This example is based on the Site 1 experiment, conducted during winter.

evaporated, dispersed within the water column, suspended at the sea surface, deposited on the bottom and discharged onto the beach. This example is based on the site 1 experiment during winter. There are two ordinate concentration scales: left for the principal components, and right for the auxiliary losses (deposited to the sediment and beached fractions).

The contamination of the coast begins after day 9 and then rapidly increases. By the end of day 15, $\sim 31$ tons of oil is discharged along the shoreline, while $\sim 36$ tons settles to the bottom. While the source is actively discharging (10 days), both evaporated and dispersed components increase with time. However, on the sea surface, the quantity of oil grows much more slowly in comparison with the water-column dispersed fraction due to evaporation to the atmosphere (the total amount of oil "In Sea" is the sum of the dispersed and the "At Surface" minus "Evaporated"). After the oil spill dries up at day 10, the amount of oil floating on the surface decreases asymptotically as evaporation, settling on the bottom, and coastal contamination continue.

The exponential growth of the beached and deposit amounts (days 9 - 12) is followed by more or less linear growth (days 12 - 14). This reflects the period of approach of the leading edge of the plume to the Crimea Peninsula and a corresponding decrease in the total amount of oil remaining at sea. 


\section{DISCUSSION AND CONCLUSIONS}

This paper describes a new pre-operational mesoscaleresolving DieCAST-SSBOM coupled oil-spill transport model based on specified wind forcing. Climatological annual-cycle winds (rather than observed winds) were used in model development since a major oil spill event has yet to occur which might be used for model validation (fortunately for the environment and unfortunately for model validation). This new high resolution/low dissipation version of the DieCAST circulation model produces realistic mesoscale circulation and variability features of the Black Sea which form the basis of water motion that transport and dissipate the oil slick in our experiments. These mesoscale structures play a significant role in the coastal and open water dynamics of the Black Sea and have a great impact on the ecology and pollution transport within the Sea.

Obviously the exact form of the oil plume will depend on the location, time and duration of the oil spill. The model is based on cyclical, climatological monthly forcing which leads to seasonal circulation patterns, which do not exactly repeat on an annual basis due to inertia and non linearities, but nevertheless the model produces characteristic, well defined, repeatable features year after year. This is a consequence of the closed nature of the basin, its characteristic topography and coastline features (such as the Crimean peninsula, for example). These circulation features are robust enough so that similar general plume patterns emerge for releases made at the same location and the same month, whatever the year. The next step in the model development is to run the integrated circulation-oil spill model forced by observed or reformulated winds such as COAMPS, NCEP or ECMWF winds (http://www.ecmwf.int/). This will be reported elsewhere.

Acknowledgements This work was supported by the NATO "Science for Peace" Program, grant CLG-981623.

\section{REFERENCES}

Aravamudan, K., P. Ray, J. Ostund, E. Newman, and W. Tucker, 1982: Break up of oil on rough seas-simplified models and step-by-step calculation. Report No CGD28-82, US Coast Guard, NTIS No. ADA118.

Audunson, T., 1979: Fate of oil spill on the Norwegian continental shelf. Proc. 1971 Oil Spill Conference, 163168, American Petroleum Institute, Los Angeles.

Cushman-Roisin, B. and K. A. Korotenko, 2007: Mesoscale-resolving simulations of summer and winter bora events in the Adriatic Sea. J. Geophys. Res., 112, C11S91, doi: 10.1029/2006JC003516. [Link]

Cushman-Roisin, B., K. A. Korotenko, C. E. Galos, and D. E. Dietrich, 2007: Simulation and characterization of the Adriatic Sea mesoscale variability. J. Geophys. Res., 112, C03S14. doi: 10.1029/2006JC003515. [Link]
Delvigne, G. A. L., 1993: Natural dispersion of oil by different sources of turbulence. Proc. 1993 Oil Spill Conference, American Petroleum Institute, Los Angeles, 415-419.

Dietrich, D. E., C. A. Lin, A. Mestas-Nunez, and D. S. Ko, 1997: A high resolution numerical study of Gulf of Mexico fronts and eddies. Meteorol. Atmos. Phys., 64, 187-201, doi: 10.1007/BF01029692. [Link]

Elliott, A. J., 1986: Shear diffusion and the spread of oil in the surface layers of the North Sea. Dt. Hydrogr. Z., 39, 113-137, doi: 10.1007/BF02408134. [Link]

Fingas, M. and B. F. J. Mullin, 1999: Water-in-oil emulsions results of formation studies and applicability to oil spill modeling. Spill Sci. Technol. Bull., 5, 81-91, doi: 10.1016/S1353-2561(98)00016-4. [Link]

Genders, S., 1988: In situ detection and tracking of oil in the water column. Oil Chem. Pollut., 4, 113-126, doi: 10.1016/S0269-8579(88)80015-7. [Link]

Ginzburg, A. I., A. G. Kostianoy, N. P. Nezlin, D. M. Soloviev, and S. V. Stanichny, 2002a: Anticyclonic eddies in the northwestern Black Sea. J. Mar. Syst., 32, 91106, doi: 10.1016/S0924-7963(02)00035-0. [Link]

Ginzburg, A. I., A. G. Kostianoy, V. G. Krivosheya, N. P. Nezlin, D. M. Soloviev, S. V. Stanichny, and V. G. Yakubenko, 2002b: Mesoscale eddies and related processes in the northeastern Black Sea. J. Mar. Syst., 32, 71-90, doi: 10.1016/S0924-7963(02)00030-1. [Link]

Jaoshvily, S., 2003: Rivers of the Black Sea. Technical Report No 71, Europ. Envir. Agency.

Korotenko, K. A., 1988: On turbulent transport of substance in non-stationary shear current in the ocean. Oceanology, 28, 545-549.

Korotenko, K. A., 1992: Adaptive model for calculation turbulence parameters in the ocean bottom layer. Oceanology, 32, 730-738.

Korotenko, K. A., R. M. Mamedov, and C. N. K. Mooers, 2001: Prediction of the dispersal of oil transport in the Caspian Sea resulting from a continuous release. Spill Sci. Technol. Bull., 6, 323-339, doi: 10.1016/S13532561(01)00050-0. [Link]

Korotenko, K. A., R. M. Mamedov, and C. N. K. Mooers, 2002: Prediction of the transport and dispersal of oil in the South Caspian Sea resulting from blowouts. Environ. Fluid Mech., 1, 383- 414, doi: 10.1023/A:1015 785909615. [Link]

Korotenko, K. A., M. J. Bowman, and D. E. Dietrich, 2003: Modeling of the circulation and transport of oil spills in the Black Sea. Oceanology, 43, 367-378.

Korotenko, K. A., R. M. Mamedov, A. E. Kontar, and L. A. Korotenko, 2004: Particle tracking method in the approach for prediction of oil slick transport in the sea: Modelling oil pollution resulting from river input. J. Mar. Syst., 48, 159-170, doi: 10.1016/j.jmarsys.2003.11.023. [Link] 
Krivosheya, V. G., V. B. Titov, I. M. Ovchinnikov, R. D. Kos'yan, and A. Y. Skirta, 2000: The influence of circulation and eddies on the depth of the upper boundary of the hydrogen sulfide zone and ventilation of aerobic waters in the Black Sea. Oceanology, 40, 767-776.

Mackay, D. and R. Matsugu. 1973: Evaporation rate of liquid hydrocarbon spills on land and water. Can. J. Chem. Eng., 51, 434-439, doi: 10.1002/cjce.54505104 07. [Link]

Mackay, D. and C. McAuliffe, 1988: Fate of hydrocarbons discharged at sea. Oil Chem. Pollut., 5, 1-20.

Monin, A. S. and A. M. Yaglom. 1965: Statistical hydromechanics. Part I, Nauka, Moscow, 640 pp.

Oguz, T., D. Aubrey, V. Latun, E. Demirov, L. Kolesnikov, H. Sur, V. Diaconu, S. Besiktepe, M. Duman, R. Limeburner, and V. Eremeev, 1994: Mesoscale circulation and thermohaline structure of the Black Sea observed during HydroBlack '91. Deep-Sea Res. I, 41, 603-628, doi: 10.1016/0967-0637(94)90045-0. [Link]

Proctor, R., R. A. Flather, and A. J. Elliot, 1994: Modelling tides and surface drift in the Arabian Gulf - Application to the Gulf oil spill. Cont. Shelf Res., 14, 531-545, doi: 10.1016/0278-4343(94)90102-3. [Link]

Staneva, J. V., D. E. Dietrich, E. V. Stanev, and M. J. Bowman, 2001: Mesoscale circulation in the Black Sea:
New results from DieCAST model simulations. $J$. Mar. Syst., 31, 137-157.

Stoyanov, D., P. Dorogan, and S. Jelescu, 1999: The Black Sea contingency planning for marine oil spills. In: Besiktepe, S. T., U. Unluata, and A. S. Bologa (Eds.), Environmental Degradation of the Black Sea: Challenges and Remedies, NATO Science Series 2, Environmental Securuty, 56, 351-367.

Wheeler, R. B., 1978: The fate of petroleum in the marine environment. Special Report, Exxon Production Research Co. Houston, USA, 124.

Yang, W. C. and H. Wang, 1977: Modeling of oil evaporation in aqueous environments. Water Res., 11, 879-887.

Zatsepin, A. G., A. I. Ginzburg, A. G. Kostianoy, V. V. Kremenetskiy, V. G. Krivosheya, S. V. Stanichny, and P.-M. Poulain, 2003: Observations of Black Sea mesoscale eddies and associated horizontal mixing. $J$. Geophys. Res., 108, 3246, doi: 10.1029/2002JC001390. [Link]

Zhurbas, V. M., A. G. Zatsepin, Yu. V. Grigor'eva, V. N. Eremeev, V. V. Kremenetsky, S. V. Motyzhev, D. M. Polyakov, P.-M. Poulain, and S. V. Stanichny, 2004: Water circulation and characteristics of currents of different scales in the upper layer of the Black Sea from drifter. Oceanology, 44, 30-45. 